\title{
Effect of the heating surface enhancement on the heat transfer coefficient for a vertical minichannel
}

\author{
Magdalena Piasecka ${ }^{1, a}$ and Kinga Strąk ${ }^{1}$ \\ ${ }^{1}$ Kielce University of Technology, Faculty of Mechatronics and Mechanical Engineering, 25-314 Kielce
}

\begin{abstract}
The aim of the paper is to estimate effect of the heating surface enhancement on FC-72 flow boiling heat transfer for a vertical minichannel $1.7 \mathrm{~mm}$ deep, $24 \mathrm{~mm}$ wide and $360 \mathrm{~mm}$ long. Two types of enhanced heating surfaces were used: one with minicavities distributed unevenly, and the other with capillary metal fibrous structure. It was to measure temperature field on the plain side of the heating surface by means of the infrared thermography and to observe the two-phase flow patterns on the enhanced foil side. The paper analyses mainly the impact of the microstructured heating surface on the heat transfer coefficient. The results are presented as heat transfer coefficient dependences on the distance along the minichannel length. The data obtained using two types of enhanced heating surfaces in experiments was compared with the data when smooth foil as the heating surface was used. The highest local values of heat transfer coefficient were obtained using enhanced foil with minicavities - in comparison to other cases. Local values of heat transfer coefficient received for capillary fibrous structure were the lowest, even compared with data obtained for smooth foil. Probably this porous structure caused local flow disturbances.
\end{abstract}

\section{Introduction}

Recently, there is a worldwide interest in compact heat exchangers with minichannels. They are characterized by many advantages such as higher efficiency and reduced size. Extensive studies are required to understand the phenomena with change of phase in such heat exchangers [1-3]. The results may be used for the designing of cooling systems with minichannels to improve their efficiency and thermal stability. Experimental investigations show that the average heat transfer coefficient in compact heat exchangers with minichannels is higher [1]. It is thus possible that compact heat exchangers with enhanced walls will have better thermal parameters. However, if the surface of the heating element is enhanced too much, i.e. it is too porous, the flow of the refrigerant and, accordingly, the whole boiling process in the minichannel, may be periodically disturbed [2]. Investigations often deals with frictional pressure drop in minichannels [3].

The use of microstructured surfaces in minichannels is known to intensify the heat transfer process. Results obtained by the application such surfaces in flow boiling in micro- or mini spaces [4-15] are not widely discussed in the specialist literature, but they are promising. The properties of a microstructured surface can be modified using chemical, thermal, mechanical or combined mechanical and thermal processes. The thermal processes include plasma spraying, electric arc spraying, sintering, laser surface texturing or electrical discharge texturing [16-24]. Enhanced heating surfaces are common in pool boiling systems. They are considered to be very efficient because of providing a large number of nucleation sites, and, in consequence, substantially increase the heat flux $[15,25-27]$.

Research on heat transfer in minichannels of the very small cross-section is considerably difficult to conduct because of the temperature measurement. In the contact temperature method a sensor placed in the minispace could disturb the fluid flow. Applying a contactless method for measuring temperature of the minichannel wall allows us to eliminate this problem. The methods that provide sufficient measurement accuracy are infrared thermography and liquid crystal thermography.

Infrared thermography (IRT) is becoming increasingly common as a contactless for measuring surface temperature. Using an infrared (IR) camera for determining of surface temperature is a very useful tool for researchers because such measurement are characterized by high sensitivity (down to $20 \mathrm{mK}$ ), low response time (down to $20 \mu \mathrm{s}$ ) and it is fully two dimensional. Error assessment is also very convenient because tangential distortions of the camera can be corrected. IR camera has become a common tool in the analysis of complex fluid flows either to evaluate convective heat fluxes on the heated wall or to investigate the behaviour of the surface flow field [28]. The IRT has been reported suitable to experimentally study the

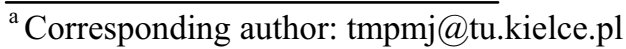


thermo-hydrodynamics of laminar flow of water in a square cross-sectional minichannel $(5 \mathrm{~mm} \times 5 \mathrm{~mm})$. It ensured high-resolution spatial measurement of the local wall temperature with the assumption of one-dimensional conduction in the transverse direction and evaluation of the heat transfer coefficient [29, 30]. The IRT has also been used to measure the wall temperature in the analysis of the increase in dryout heat flux for four fluids in two small diameter tubes (diameters of $1.15 \mathrm{~mm}$ and $2.3 \mathrm{~mm}$ ) [31]. In [32] the IRT has been applied to determine the local heat transfer coefficients during the Taylor bubble train flow in a square cross-sectional minichannel $(5 \mathrm{~mm}$ x $5 \mathrm{~mm}$ ). IR camera was used to determine the $\mathrm{CHF}$ conditions and the temperature fields of the heater surfaces [33]. It has been found that is very useful technique to study enhanced boiling heat transfer and critical heat flux (CHF) for reduced graphene oxide, graphene, and $\mathrm{SiC}$-coated surfaces. The IRT was also applied to visualize temperature field to study the subcooled flow boiling in a vertical square channel; it was used for the validation of CFD simulations and for the improvement and development of turbulence models under subcooled boiling conditions [34]. Researchers in [35] stated that the IRT was well suited for measurement of two-phase flow parameters in a convective boiling system. In [36] the local Nusselt numbers were obtained using IRT in two-phase non-boiling slug flows under constant flux. Researchers in $[37,38]$ have used IRT to study pool boiling on a fin.

\section{Experimental stand, methodology and uncertainties}

\subsection{Experimental stand}

The experimental stand (figure 1) is composed of several systems: the test loop in which Fluorinert FC-72 circulates as the working fluid, the calibration loop, the data and image acquisition system, the supply and control system and the lighting system, described in [11-16]. The test loop consists of: a rotary pump, a heat exchanger, a compensating tank, rotameters, a filter and a deaerator. The data and image acquisition system comprised of FLIR SC640 infrared camera, SLR Canon EOS 550D camera, DaqLab 2005 data acquisition station, a computer with special software and a lighting system.

\subsection{The testing module with minichannels}

The most important part of the system is the testing module (figure 2) which comprises two parallel vertically-oriented minichannels each $1.7 \mathrm{~mm}$ deep, 24 $\mathrm{mm}$ wide and $360 \mathrm{~mm}$ long, as shown in figure 2 . The heating element for FC-72 flowing in minichannels is the foil (2). Infrared thermography is used to observe changes in temperature on the outer smooth side of the foil in one minichannel and this data is taken account in further calculations and analyses. Foil temperature is measured by IR camera in the central, axially symmetric, part of the channel (approx. $10 \mathrm{~mm}$ x $350 \mathrm{~mm}$ ). The surface of foil is coated with black paint (9) to gain an emissivity of 0.83 [39]. The minichannel is reinforced on both sides with narrow glass panels to prevent the heating foil from deforming.

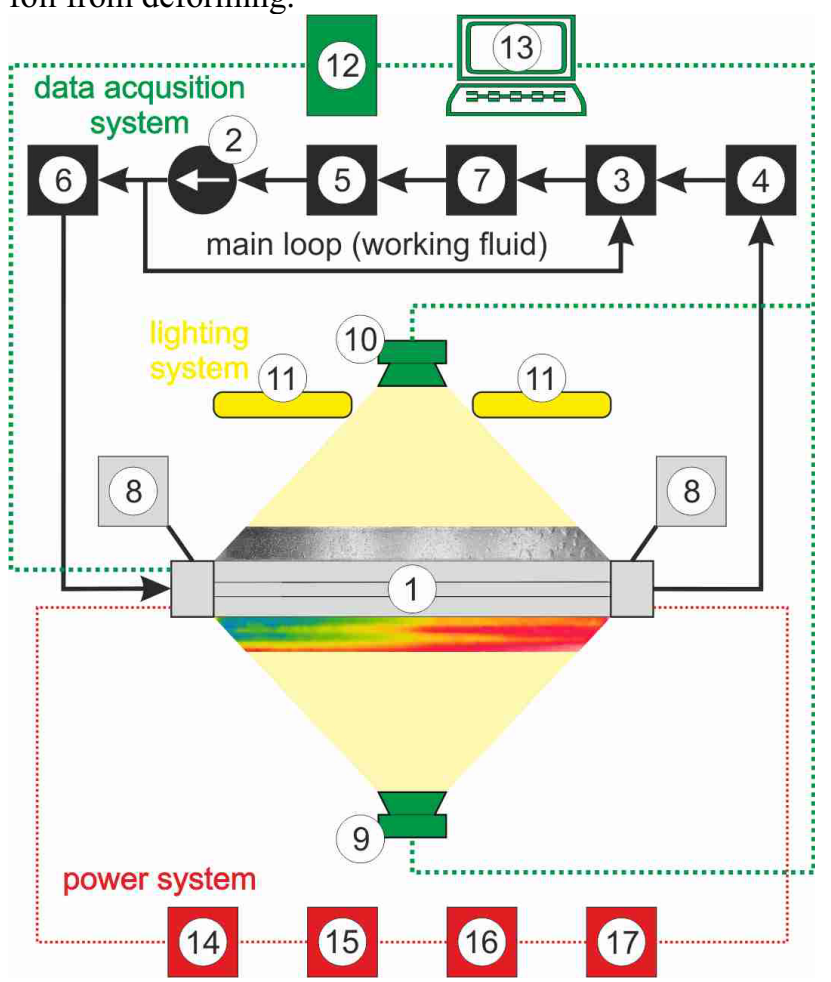

Figure 1. Schematic diagram of the main loops of the experimental set-up, 1 - testing module with minichannels; 2 - rotary pump; 3 - compensating tank/pressure regulator; 4 - tube-type heat exchanger, 5 - filter, 6 - rotameters; 7 - deaerator, 8 - pressure converter, 9 - IR camera, 10 - digital SLR camera, 11 - halogen lamp, 12 - data acquisition station, 13 - computer, 14 - inverter welder, 15 - shunt, 16 - ammeter, 17 - voltmeter.
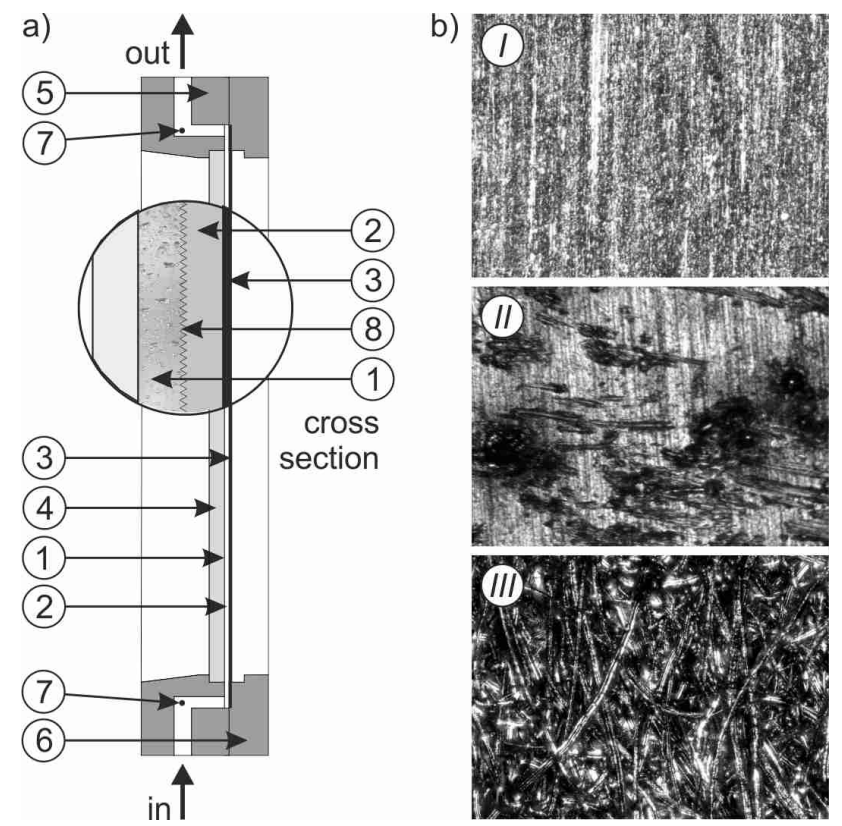

Figure 2. Schematic diagram of the testing module with minichannels: 1 - minichannel, 2 - heating foil, 3 - black paint 
layer, 4 - glass pane, 5 - channel body, 6 - front cover, 7 - thermocouple, 8 - enhanced surface, b) photos of: the smooth foil (I), enhanced foils (II, III) with: minicavities (II) and capillary metal fibrous structure (III).

The other side of the minichannels, where a twophase flow occurs on the enhanced surface of the foil in contact with the fluid, are observed through another two glass panes. K-type thermocouples and pressure converters are installed at the inlet and outlet of the minichannel.

\subsection{Characteristic of the heating foil enhancement}

The heating element for FC-72 flowing in the minichannel was the thin alloy foil (approx. $0.1 \mathrm{~mm}$ in depth) designated as Haynes-230, with the smooth surface roughness of $R a=0.121 \mu \mathrm{m}$, see figure 2.b (I).

Two types of enhanced heating surface were used: one with minicavities, and another with capillary metal fibrous structure.

The minicavities, see figure 2.b (II), produced by spark erosion over the whole surface area of the foil using an arcograph were distributed unevenly and their dimensions varied. The rims of resolidified melt from the electrode and the foil were several $\mu \mathrm{m}$ in height, with a maximum height being $5 \mu \mathrm{m}$. The craters were usually less than $1 \mu \mathrm{m}$ deep [16].

The length of the capillary stainless steel fibrous structure, see figure $2 . \mathrm{b}$ (III), is usually up to $2 \mathrm{~cm}$. They were spot welded with a microwelder and rolled to a thickness of 0.15-0.2 mm.

\subsection{Experimental methodology}

During experimental series, after the deaeration, the working fluid (FC-72) flows laminarly along the minichannel. When flow rate and the pressure are fixed, there is a gradual increase in the electric power supplied to the heating foil followed by an increase in the heat flux transferred to the fluid in the minichannel. This leads to the onset of nucleate boiling and the heat transfer enhancement. It is possible to measure the distribution of temperature on the smooth foil surface due to infrared thermography. The flow structure is observed simultaneously on the opposite side of the minichannel (on the smooth or enhanced foil surface in contact with the fluid).

\subsection{Experimental uncertainties}

The images taken with a FLIR SC640 infrared camera system operating in the spectral range from $7.5 \mu \mathrm{m}$ to $13 \mu \mathrm{m}$ were recorded in a digital system with an image frequency of $30 \mathrm{~Hz}$. The accuracy of the camera was $\pm 2 \mathrm{~K}$ or $\pm 2 \%$ of reading. The camera can be used for remote real time measurement of temperature with a thermal resolution ranging from $0.06{ }^{\circ} \mathrm{C}$ to $30{ }^{\circ} \mathrm{C}$ [40].

\section{Local heat transfer coefficients determination}

Various methods of the determination of the local heat transfer coefficients have been proposed [41- 43]. Here, the simple one-dimensional approach was used. The resulting heat transfer coefficient for the saturated boiling was calculated according to the following equation:

$$
\alpha_{I R T}(x)=\frac{q_{w_{-} I R T}}{T_{F}^{I R T}\left(x, \delta_{G}\right)-T_{s a t}(x)}
$$

where $T_{F}^{I R T}$ - foil temperature measured by infrared thermography, $q_{w_{-} I R T}-$ heat flux transferred to the fluid in the IRT minichannel, $T_{s a t}(x)$ - saturation temperature determined on the basis of the linear distribution of pressure along the length of the minichannel from the inlet to the outlet.

The heat transferred to the fluid was calculated as:

$$
q_{w_{-} I R T}=\frac{I \cdot \Delta U}{A_{F_{-} I R T}}-q_{w l}
$$

where $I$ - current, $\Delta U$ - voltage drop, $A_{F-I R T}$ - surface area of the heating foil in the IRT minichannel, $q_{w l}$ - the heat lost to the surroundings in the IRT minichannel [43].

The central part of the heating foil where the surface temperature is measured with the infrared camera $(10 \mathrm{~mm}$ $\mathrm{x} 350 \mathrm{~mm}$ ) is not insulated. Therefore, the loss of heat to the surroundings is the greatest. It was estimated as $1.3 \%$ of the heat flux density [43].

The local heat transfer coefficients obtained for the single phase convection, boiling incipience and subcooled boiling region were analysed in [41].

\section{Results}

Figures 3-5 show the results selected for the analysis plotted as the heat transfer coefficient versus the distance along the length of the minichannel. During the measurement series, thermal and flow parameters were nearly identical. The heat flux density was the same for experiments with minicavities on the enhanced foil surface and for the smooth foil.

Figure 3 presents the data obtained for the enhanced surface with minicavities and for the smooth foil. The local heat transfer coefficients obtained for capillary fibrous structure differ significantly from those for other foil surface types.

The heat flux supplied to the enhanced foil with capillary fibrous structure was much lower than those supplied to the smooth foil and enhanced foil with 
minicavities. For that reason, it is shown separately in figure 4.

Figure 5 presents local heat transfer coefficients as a function of the minichannel length for all the heating surfaces: two enhanced foils (with minicavities, with capillary stainless steel fibrous structure) and the smooth foil.

In the fully developed nucleate boiling, the heat transfer coefficient was the highest but then it decreased sharply with an increase in the distance from the channel inlet, which was accompanied by an increase in the vapour volume fraction in the two-phase flow mixture, as shown in figures $3-4$. As the boiling process proceeded, partial dryout and a reduction in heat transfer were reported [13-15], as in the works of other researchers [44-48]. Finally, the heat transfer coefficient decreased steadily to much lower values and heat transfer returned to single-phase forced convection. The lowest values of the coefficient were noticed at the minichannel outlet.

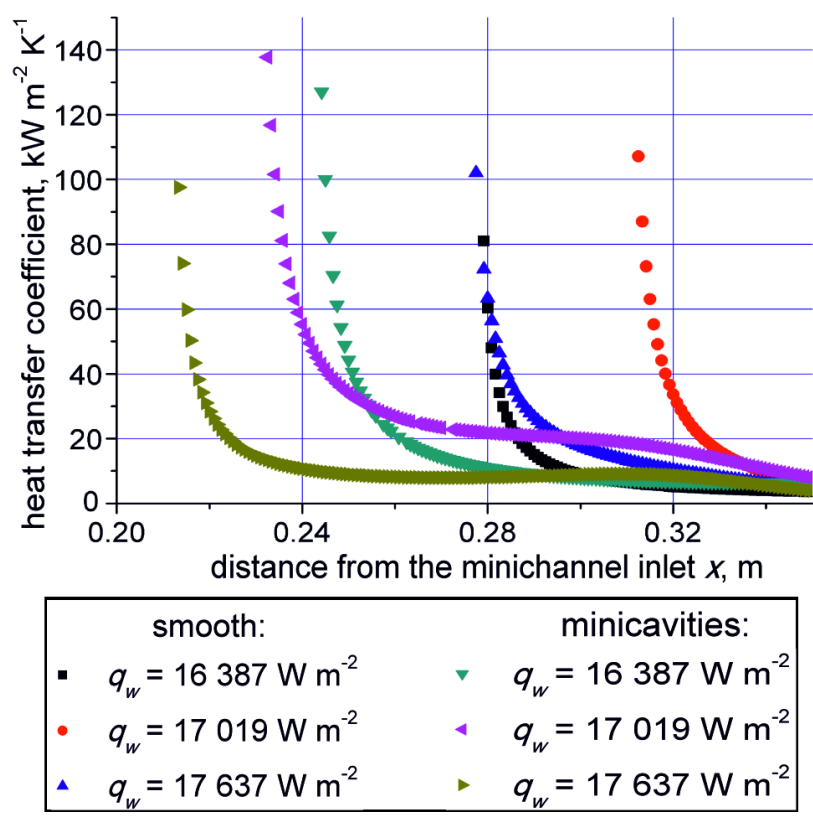

Figure 3. Heat transfer coefficient vs. the minichannel length determined for the smooth foil and the enhanced foil with minicavities.
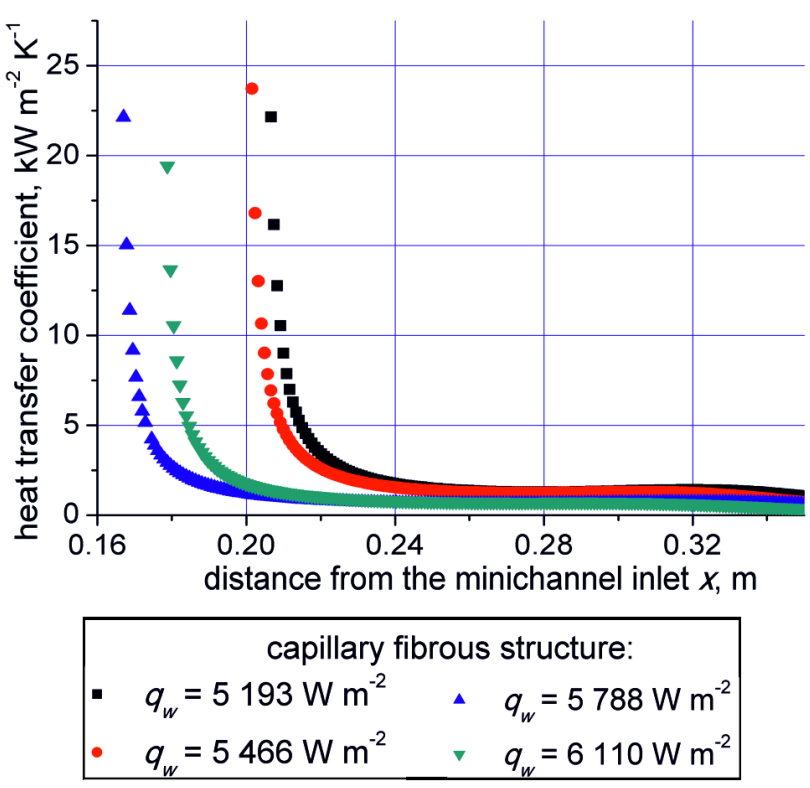

Figure 4. Heat transfer coefficient vs. the minichannel length for the enhanced foil with capillary stainless steel fibrous structure.

The highest local values of heat transfer coefficient were obtained with using enhanced foil with minicavities - in comparison to other cases. Local values of heat transfer coefficient received for capillary fibrous structure were the lowest, even compared with data obtained for smooth foil. Probably this porous structure caused local flow disturbances during fluid flow along the minichannel. The formation of vapour bubbles could also affect heat transfer process causing its deterioration.

From the results of the pool boiling experiments it occurs that for surfaces with minicavities the geometrical parameters need to be selected to match specific liquids. For example, smaller diameters of cavities are suitable for liquids with lower surface tension (refrigerants) [25] 


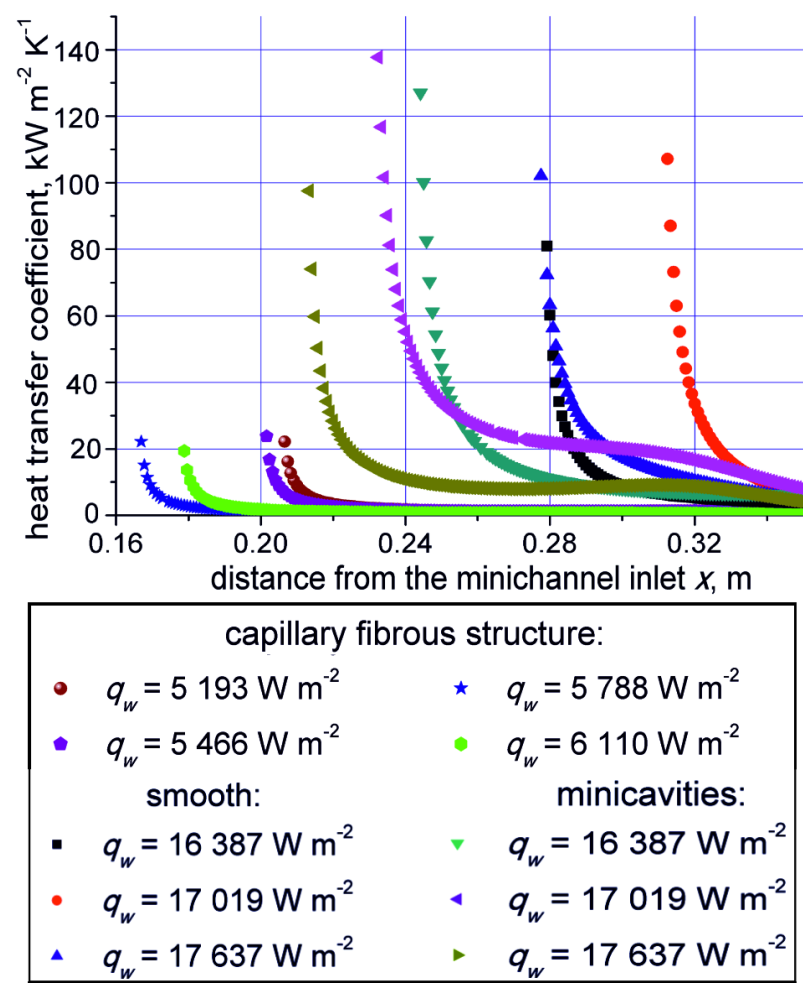

Figure 5. Heat transfer coefficient vs. the minichannel length for: the smooth foil, the enhanced foil with minicavities, the enhanced foil with capillary stainless steel fibrous structure.

\section{Conclusions}

The aim of the paper was to estimate effect of the heating surface enhancement on FC-72 flow boiling heat transfer for a vertical minichannel. Two types of enhanced heating surfaces were used: one with minicavities distributed unevenly, and the other with capillary metal fibrous structure. It was to measure temperature field on the plain side of the heating surface by means of the infrared thermography and to observe the two-phase flow patterns on the enhanced foil side. The impact of the microstructured heating surface on the heat transfer coefficient were analyzed. The results are presented as heat transfer coefficient dependences on the distance along the minichannel length. Data obtained using two types of enhanced heating surfaces in experiments was compared with the data when smooth foil as the heating surface was used. The highest local values of heat transfer coefficient were obtained using the enhanced foil with minicavities - in comparison to other cases. Local values of heat transfer coefficient received for capillary fibrous structure were the lowest, even compared with data obtained for smooth foil. Probably this porous structure caused local flow disturbances during fluid flow along the minichannel.

\section{Acknowledgements}

The research reported herein was supported by a grant from the National Scientific Center (No. DEC2013/09/B/ST8/02825).

\section{References}

1. T. Bohdal, Annual Set Env. Protect. 15, 107-126 (2013)

2. T. Bohdal, W. Kuczyński, Heat Tran. Eng. 32 (5), 359-368 (2011)

3. K. Dutkowski, Heat Tran. Eng. 31, 321-330 (2010)

4. C. N. Ammerman, S. M. You, J. Heat Tran. 123, 976-983 (2001)

5. A. Kosar, C.-J. Kuo, Y. Peles, Int. J. Heat Mass Tran. 48, 4867-4886 (2005)

6. C.-J. Kuo., Y. Peles, Int. J. Heat Mass Tran. 50, 4513-4526 (2007)

7. V. Khanikar, I. Mudawar, T. Fisher, Int. J. Heat Mass Tran. 52, 3805-3817 (2009)

8. H. Wang, R. B. Peterson, IEEE Trans. Compon. Pack. Techn. 33, 784-793 (2010)

9. Y. Sun, L. Zhang, H. Xu, X. Zhong, Exp. Therm. Fluid Sci. 35, 1418-1426 (2011)

10. Y. Sun, L. Zhang, H. Xu, X. Zhong, Int. J. Therm. Sci. 50, 881-889 (2011)

11. M. Piasecka, Exp. Heat Tran. 27, 231-255 (2014)

12. M. Piasecka, Heat Tran. Eng. 35 (10), 903-912 (2014)

13. M. Piasecka, Int. J. Heat Mass Tran. 81, 114-121 (2015)

14. M. Piasecka, Int. J. Refrig. 56, 198-212 (2015)

15. M. Piasecka, Ann. Nucl. Energy 73, 282-293 (2014)

16. M. Piasecka, Adv. Mater. Research 874, 95-100 (2014)

17. W. Depczyński, Proc. 23rd Int. Conf. Metallurgy Materials METAL 2014, Poland (2014)

18. W. Depczyński, S. Spadło, P. Młynarczyk, E. Ziach, Proc. 24th Int. Conf. Metallurgy Materials METAL 2015, Poland (2015)

19. B. Grabas, Arch. Metall. Mater. 60 (1), 33-39 (2015)

20. B. Grabas, Exp. Therm. Fluid Sci. 68, 499-508 (2015)

21. B. Grabas, Adv. Mater. Research 874, 71-75 (2014)

22. N. Radek, J. Pietraszek, B. Antoszewski, Adv. Mater. Research 874, 29-34 (2014)

23. J. Pietraszek, N. Radek, K. Bartkowiak, Solid State Phen. 197, 198-202 (2013)

24. N. Radek, B. Antoszewski, Kovove MaterialyMetallic Materials 47 (1), 31-38 (2009)

25. R. Pastuszko, M. Piasecka, J. Physics Conf. Ser. 395, paper No. 012137 (2012)

26. R. Pastuszko, M. Wójcik, Exp. Therm. Fluid Sci. 63, 34-44 (2015)

27. R. Pastuszko, EPJ Web Conf. 45, paper No. 01020 (2013)

28. G. M. Carlomagno, G. Cardone, Exp. Fluids 49, 1187-1218 (2010)

29. B. Mehta, A. Dhyani, S. Khandekar, Proc. 21st National \& 10th ISHMT-ASME Heat Mass Tran. Conf. Madras, India, paper ISHMT_IND_02_041 (2011)

30. B. Mehta, S. Khandekar, Exp. Therm. Fluid Sci. 42, 219-229 (2012)

31. D. Mikielewicz, J. Wajs, M. Gliński, A.-B. R.S Zrooga, Exp. Therm. Fluid Sci. 44, 556-564 (2014) 
32. B. Mehta, S. Khandekar, Int. J. Heat Fluid Flow 45, 41-52 (2014)

33. H. Seo, J. H. Chu, S.-Y. Kwon, I. Ch. Bang, Int. J. Heat Mass Tran. 82, 490-502 (2015)

34. C. E. Estrada-Perez, J. Yoo, Y. A. Hassan, Int. J. Multiph. Flow 73, 17-33 (2015)

35. J. Yoo, C. E. Estrada-Perez, Y. A. Hassan, Int. J. Therm. Sci. 90, 248-266 (2015)

36. P. A. Walsh, E. J. Walsh., Y. S. Muzychka, Int. J. Heat Mass Tran. 53, 3193-3201 (2010)

37. T. Orzechowski, Exp. Therm. Fluid Sci. 31 (8), 947955 (2007)

38. T. Orzechowski, A. Tyburczyk, ISI Master Journal List 87 (7), 48-51 (2011)

39. T. Orzechowski, Heat transfer on ribs with microstructured surface, Monographs, studies, hearings 39 (in Polish) (the Publishing House of the Kielce Univ. Techn., Kielce, Poland, 2003)

40. User's manual ThermaCam B640, P640, SC640, Publ. No 155850 Rev.a 201-ENGLISH (EN) (2007)

41. M. Piasecka, B. Maciejewska, Exp. Therm. Fluid Sci. 68, 459-467 (2015)

42. S. Hożejowska, M. Piasecka, Heat Mass Tran. 50, 1053-1063 (2014)

43. K. Ziętala, M. Piasecka, Trans. Inst. Fluid-Flow Machinery, 128 (to be published)

44. S. Hożejowska, R. Kaniowski, M. E. Poniewski, Int. J. Numer. Method Heat Fluid Flow 24, 811-824 (2014)

45. M. E. Steinke, S. G. Kandlikar, J. Heat Tran. 126 (4), 518-526 (2004)

46. M. Cortina D1'az, J. Schmidt, Int. J. Heat Fluid Flow 28, 95-102 (2007)

47. E. Sobierska, R. Kulenovic, R. Mertz, M. Groll, Exp. Therm. Fluid Sci. 31, 111-119 (2006)

48. E. Sobierska, R. Kulenovic, R. Mertz, Int. J. Therm. Sci. 46, 1172-1181 (2007) 